\title{
A comparison of the effect of logistic strategy and logistics integration on firm competitiveness in the USA and China
}

John E. Spillan

School of Business, University of North Carolina at Pembroke, Pembroke, North Carolina, USA

Michael A. McGinnis

The Pennsylvania State University, New Kensington, Pennsylvania, USA

\section{Ali Kara}

Business Administration, The Pennsylvania State University, York, Pennsylvania, USA, and

George Liu Yi

School of Economics and Management, Xi'an Shiyou University, Xi'an, China

\begin{abstract}
Purpose - The purpose of this manuscript is to empirically compare logistics strategies in Chinese and US manufacturing firms and the outcomes of these strategies to test the underlying factor structure and measurement equivalences of Bowersox/Daugherty model and its relationship with critical success factors.

Design/methodology/approach - A structured questionnaire was used to gather data from Chinese and American logistics managers. Using confirmatory factor analysis (CFA), the authors compared the three dimensions of the overall logistics strategy (OLS) - process strategy, market strategy, and information strategy - in two countries. A structural equation model (SEM) was then used to assess the impact of OLS on perceived competitiveness in two countries.

Findings - Although the economic, political, and cultural dimensions of the two countries differed substantially, the findings were similar. Data from both countries provided strong support for the three dimensions of overall logistic strategy (OLS). In addition, it was found that OLS, when combined with logistics coordination effectiveness (LCE) and customer service effectiveness (CSE), contributes to organizational effectiveness (COMP).

Practical implications - This research provides insights into comparative logistics in two large disparate economies and provides support for the Bowersox/Daugherty logistics/supply chain management typology.

Originality/value - This manuscript provides insights into comparative logistics/supply chain management that have not been previously reported through empirical research.

Keywords Logistics strategy, Logistics process integration, Logistics information integration, Competitive advantage, Comparative logistics/supply chain management, Distribution management, Supply chain management, United States of America, China

Paper type Research paper
\end{abstract}

\section{Introduction}

The significance of logistics has evolved from a more passive and cost minimization oriented activity to a key success factor for firm competitiveness. More recently it has

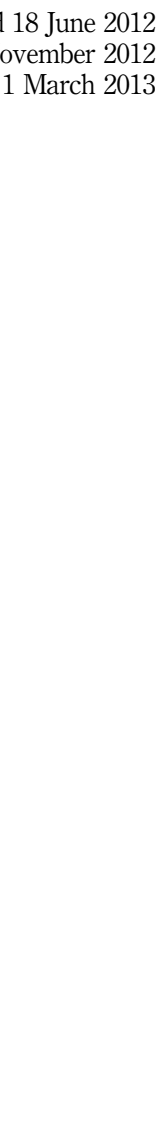

Received 18 June 2012

Revised 29 November 2012 Accepted 1 March 2013

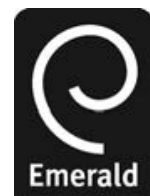

The International Journal of Logistics

Management Vol. 24 No. 2, 2013 pp. $153-179$

(C) Emerald Group Publishing Limited 0957-4093 DOI 10.1108/IJLM-06-2012-0045 
IJLM

24,2

154

become an integral part of a firm's strategic planning process (Carter et al., 1997). Highly globalized market environments now offer significant opportunities for multinational companies to move their manufacturing and distribution activities throughout the world especially among developing and emerging markets. Even within this context researchers argue that the global manufacturing strategies alone may not be effective if not supported by successful logistics/supply-chain management strategies. While basic logistics decisions mainly deal with physical movement of the products, Bowersox and Daugherty (1987) emphasized adoption of a more comprehensive framework for logistics strategy that includes cost management, a focus on simplifying transactions faced by customers, and information exchange throughout the channel.

Logistics is a critical success factor in international markets because of the different cultural, legal, physical, and distribution environments. As such, cross-cultural logistics studies have significant potential to enrich the understanding for practitioners, teachers, and researchers in terms of logistics systems and strategies that can be applied as a factor in a firm's competitiveness in different national environments. In comparison to cross-cultural research in other disciplines, such as management and marketing, Luo et al.'s (2001) review suggests that the cross-cultural study of logistics is, at best, in its infancy stage. Two more recent studies have included Chinese subjects to examine supply-chain management operationalize internal and external integration. In the first study, Chen et al. (2009b) used Chinese subjects in their research to conceptualize internal and external supply-chain management. They concluded that internal process integration facilitates external process integration, which in turn increases firm performance. A simplified model was proposed as a possible model for future research. In the second study, Chen et al. (2009a) used USA and Chinese subjects to further examined the potential of a process-oriented prospective. They found that a combination of cost orientation and customer orientation have a greater impact on supply-chain integration than either does individually, and this process integration impacts firm performance by impacting efficiency, effectiveness, and integration. A final observation of the Chen et al. (2009a) study was that Chinese and American subjects fundamentally agreed about the nature of supply-chain integration.

The aforementioned studies relate to a thread of research that focusses on strategy-structure-process (SSP) as an approach to understanding supply-chain management. In another study, Rodrigues et al. (2004) used empirical data to assess information systems, measurement systems, and internal operations integration. These authors concluded that integrated systems and integrated measurement systems contributed to internal operations integration, and that integrated measurement systems contributed to external operations integration. Defee and Stank (2005) also used the SSP literature to postulate an internal supply-chain environmental model and suggested that future research test that model. Rai et al. (2006) based their research on an information technology (IT) model that focussed on supply-chain management IT and process integration to enhance firm performance. Results supported the research model.

Kim (2006) also used a SSP approach to assess supply-chain capability and corporate competitiveness in South Korea. It was concluded that supply-chain integration is an intervening variable that leads to improved firm performance, and that close alignment with the supply-chain is crucial even when the firm's competitive and supply-chain capabilities are strong. Agan's (2011) research sought to assess 
causal models that explain supply-chain integration, and how supply-chain integration will improve performance. It was concluded that supply-chain integration can be a source of competitive advantage but that an IT and a market orientation are required for achieving supply-chain integration.

A second stream of research was inspired by the earlier work of Bowersox and Daugherty (1987). Both streams of research offer insights into the issues raised by Stock (2002), namely that logistics (and supply-chain) management needs to develop theory-like generalizations and examine interfaces and roles of logistics (and supplychain) management within the organization and among supply-chain members. To date insights into the management of logistics/supply-chain management have generally focussed on two broad approaches, a relatively structured approach as suggested by Bowersox and Daugherty and subsequent research as well as a process approach as suggested in the SSP framework. Both approaches offer insights into the issues raised by Stock (2002).

The goal of this manuscript is to review ongoing series of studies that assess logistics/supply-chain management strategies in different countries and then empirically compare Chinese and US logistics/supply-chain management strategies. As shown by earlier research by Chen et al. (2009a,b), and Kim (2006) the process approach to cross-cultural logistics/supply-chain management has potential. In the subsequent paragraphs, the authors identify additional research among cross-cultural logistics/supply-chain management domains. Additionally, they provide comparative studies regarding various aspects of Chinese and American logistics/supply-chain management strategy.

Two recent studies (Kohn et al., 2011; McGinnis et al., 2012) investigate the role of overall logistics strategy (OLS) on logistics coordination effectiveness (LCE), customer service effectiveness (CSE), and organizational competitive responsiveness. Using multi-year data collected in the USA, and multi-country data collected from Turkey and Guatemala, their findings showed that overall logistic strategy as conceptualized by the Bowersox/Daugherty dimensions, had significant effect on a firm's competitiveness through logistics coordination and customer service paths. Validating the results of these studies in China's large economy should be critically valuable for practitioners and researchers alike. How well does the OLS apply to large emerging Chinese market environments? This important empirical question is the focus of the research reported in this manuscript.

The manuscript is organized into the following six sections. The next section provides an overview of the characteristics of the USA and China. Next, empirical literature relevant to logistics/supply-chain management strategy and cross-cultural research is reviewed. The following two sections describe the research methodology and the analysis and results. The final two sections discuss the relevance and implications of this research and then provide suggestions for future research.

\section{Two different contexts: China and the USA}

China is the longest lasting continuous civilization in the world from ancient times, with evidence of farming dating back to $7000 \mathrm{BC}$ and written records dating from 2100 BC. Much of China's history can be described as a series of dynasties with alternating periods of political harmony and disharmony. Modern Chinese history dates from the Republic of China in 1912 following the upraising of 1911. The period from 1911 to 1949 is characterized by internal political strife, civil war, the Sino-Japanese War (which became part of second World War), and continuing civil war, 
IJLM

24,2

156 which ended with the Chinese Communist victory and establishment of the People's Republic of China.

Although some signs of slowing down have recently been observed, China's economy has been growing at nearly double-digit rate during the last three decades. With its large population and fast economic growth rate, China has become a popular destination for manufacturing and distribution (Wang et al., 2006). Logistics and distribution in China have also grown rapidly as a result of significant expansion of manufacturing and marketing activities by multinational companies. Although the logistics infrastructure in China has been insufficient, recent developments and efforts by the government to encourage investment into the logistics industry have resulted in significant improvements. The period from 1949 included involvement in a regional war from 1950 to 1953, internal struggles including the Great Leap Forward and the Cultural Revolution, and a transition from a planned economy to "market socialism." The foundation of current Chinese economic thought policy is the "four modernizations" which were formerly pronounced in 1976. The four modernizations focus on agriculture, industry, science and technology, and national defense. To a large extent, in the authors' opinion, the four modernizations are the basis for current Chinese business practices and the foundation for understanding the context of the research presented in this manuscript.

Prior to 1978, China had a three tiered distribution system (Jiang and Prater, 2002). Within this arrangement, only the state owned wholesalers could provide logistical services. Their activities were limited to only warehousing and delivery. Essentially the three-tiered system looked like this: first, Tier 1 - distribution and delivery for large cities like Shanghai and other large designated cities; second, Tier 2 - distribution suppliers were located in provincial capitals and medium size cities. Within in these area there were regional distribution mechanisms where goods were stored and transported to major urban areas; and third, Tier 3 - distribution sites that operated in smaller towns and cities and provided storage and delivery to retailers (Jiang and Prater, 2002).

The tiered system was very bureaucratic and its operation limited the flows in distribution of goods and the connections with other distribution networks associated with the tier system. Consumer satisfaction was not a priority in this system. Getting goods to a point and distributing them was the main focus. The three-tiered system has evolved and a commodity circulation system has emerged where the government/ state was involved but began to allow private enterprises to operate (Jiang and Prater, 2002). In 1984 businesses were given more autonomy and regulations were loosened. Distributors and manufacturers could now participate in the import/export activities. This enabled China to play an increasingly important role in world commerce. China's joining the World Trade Organization (WTO) in 2001 eliminated some restrictions on foreign logistics investment and opened opportunities for free access to supply-chain management system implementation. By 2005 all restrictions had been eliminated and the economy was opened to a wide range of international and domestic commercial activity. This permitted major expansions of logistical and distribution activities among private, foreign, and local enterprises (Kearney, 2010). China is presently positioned for major growth in the supply-chain area over the next five years. Several companies have begun developing more innovative strategies, which will provide competitive advantages in the dynamic Chinese economy.

Compared to China, the USA has a well-established network of logistics systems. Economic deregulation of the transportation and warehousing industries during the 
late 1970s and early 1980s provide the opportunity for the blending of transportation, warehousing, and distribution activities so that a wide range of third-party logistics (3PL) could develop to facilitate the coordination of logistics activities throughout the supply chain. This resulted in the emergence of supply-chain management as a concept that expanded on the concept of logistics management. In comparison to China, the USA has a well-developed and integrated logistics network whose major weaknesses are and aging infrastructure and is slow to adapt to changing markets and distribution patterns.

However, China's supply-chain management industry is in early stages of development, with fragmented and uncoordinated logistical activities that need to be rationalized (Kearney, 2010). Executives have a great deal of interest in establishing strategic logistical areas in China because they offer competitive advantage for those who participate (Kearney, 2010). Nearly all have the transportation and logistical operations in China are directing their efforts toward growth and meeting customer needs. Many recognize that the establishment of information technology management (ITM) has become the central component in the success of the SCM in China and there will continue to be a concerted effort to make ITM a critical component of the SCM (Jiang and Prater, 2002).

China has a shortage of logistics and supply-chain management expertise. This coupled with an inadequate supply chain and logistical infrastructure and a lack of a skilled workforce poses a significant challenge for future development (Kam et al., 2010). Both opportunities and threats exist but if the recent past is prologue, China will move diligently forward and overcome its supply-chain management obstacles and become a force in supply-chain management and the distribution of goods in world markets. In contrast, the USA is a well-established, large, and dynamic economy.

When compared to China, the USA is a relatively new civilization with a relatively well-established history of business practice. Business practice evolved largely from English Common Law and has been legislatively modified beginning in the late 1800s. Moreover, the USA has evolved from primarily an agricultural society to a manufacturing focussed nation, and then to a service economy beginning in the mid-1800s, industrialization occurred during the last half of the 1800s and early 1900s. The major change in the US' economic power was a result of Second World War. By 1945 most of Europe's industrial base had been devastated by war, lost as war reparations (in the case of Germany), worn out (in the case of Great Britain), relocated due to invasion and heavily focussed on military output (in the case of the USSR). In Asia, China was wrought with civil war, Japan's economic base had been destroyed, and most European colonies were struggling for (or after) independence. Of the Second World War participants, the only country to emerge with a first-rate, modern, undamaged, economic base was the USA. This resulted in the emergence of the USA as the strongest economic power in the world. This dominance continued through the 1950s and began to decline during the 1960s, 1970s, and 1980s as other nations recovered from the devastation of Second World War.

Besides the different histories of political and economic development, China, and the USA vary in population (China's is over four times as large), percentage of urban population (the US' is much greater), makeup of the labor force (a greater percentage of the US' workforce is in services oriented and less is in manufacturing and agricultural), gross domestic product, and the corruption levels. Table I summarizes these results.

In addition, the cultural dimensions of these two largest economies of the world differ. As shown in Table II, the cultures of China and the USA differ in many ways, 


\section{IJLM \\ 24,2}

158

\begin{tabular}{|c|c|}
\hline Category & China \\
\hline Area (sq km/sq miles) & $\begin{array}{l}9,596,961 \text { (slightly smaller } \\
\text { than the USA) }\end{array}$ \\
\hline Population & $1,343,239,923$ est. \\
\hline Percentage of population urban & $47 \%(2010)$ \\
\hline Make up of labor force & $\begin{array}{l}\text { Agriculture: } 10.1 \% \text { industry: } \\
46.8 \% \text { services: } 43.1 \%\end{array}$ \\
\hline Gross domestic product & $\$ 6.989$ trillion est. \\
\hline Climate & Extremely diverse \\
\hline Railroads (km/miles) & $86,000 / 53,439$ \\
\hline Paved roads (km/miles) & $3,056,300 / 1,899,147$ \\
\hline 2011 Public-Sector Corruption & 3.6: 75 of 182 countries. Higher \\
\hline $\begin{array}{l}\text { Index. An indication of } \\
\text { domestic public corruption }\end{array}$ & number $>$ less corrupt \\
\hline 2011 Bribery Payers Index. An & 6.5: 27 of 28 countries. Between \\
\hline index of likelihood to bribe in & Russia and Mexico higher \\
\hline $\begin{array}{l}\text { host countries when engaging } \\
\text { in international trade. }\end{array}$ & $\begin{array}{l}\text { number }>\text { less bribery in the } \\
\text { private sector }\end{array}$ \\
\hline
\end{tabular}

USA

$9,826,675 / 3,807,983$

$313,847,465$ est.

$82 \%$

Agriculture: $0.7 \%$ industry:

$20.3 \%$ services: $79.1 \%$

$\$ 15.06$ trillion est.

Varied

224,792/139,683

$4,374,784 / 2,718,438$

7.1: 24 of 182 countries

8.1: 10 of 28 counties

Comparable to France

and Singapore
Table I.

Selected comparisons of the USA and China
Sources: Categories "Area” through "Paved Roads": US Central Intelligence Agency (2012); Categories "2011 Public-sector Corruption Index" and "2011 Bribery Index": Transparency International (2012)

and are similar in one way. In general, the USA culture is known to be low on power distance (less tolerant of unequally distributed power), high on uncertainty avoidance (more comfortable in unstructured situations), high on individualism (more likely to be concerned with self rather than group), and low on long-term orientation (emphasis on quick results rather than long-term goals). Both Chinese and US cultures are similar on masculinity/femininity (success driven rather concerns for caring and the quality of life).

The aforementioned discussion illustrates that the contrast between Chinese and USA is striking. On one hand China has emerged, as a strong economic power in a few decades while the USA has been a dominant economic power for over half a century. Furthermore, the cultures of the two countries are considerably different. The consequence of these differences means that any comparisons of commercial practices between these two large disparate economies could provide insights into practices that are either common across economies and cultures or unique to countries with disparate economic histories and cultures.

In summary, China is a large economy that is rapidly growing but lacks the highest level of managerial sophistication and the other, the USA, is a large economy that is mature with a high level of sophistication. Comparing the logistics strategies of these two large, but different, countries could provide insights into concepts in logistics/ supply-chain management strategy that are widespread across cultures. It can also provide an explanation or understanding those concepts that are likely to be idiosyncratic to specific countries.

The balance of manuscript empirically compares logistics strategies in China and the USA. It is organized into four sections. The literature review examines the empirical literature relative to the Bowersox/Daugherty typology and perspectives on Chinese logistics. The research methodology portion of the manuscript discusses of 


\begin{tabular}{|c|c|c|c|c|}
\hline \multirow{2}{*}{$\begin{array}{l}\text { Dimension name and } \\
\text { brief description }\end{array}$} & \multicolumn{2}{|c|}{ Example attributes } & \multirow{2}{*}{$\begin{array}{c}\text { Dimension scores } \\
\text { US/Chinese } \\
\text { subjects }^{\mathrm{a}} \\
\end{array}$} & \multirow{2}{*}{$\begin{array}{l}\text { Logistic strategy } \\
\text { and integration }\end{array}$} \\
\hline & Low score & High score & & \\
\hline \multirow{2}{*}{$\begin{array}{l}\text { Power distance: the } \\
\text { extent that those less } \\
\text { powerful accept that } \\
\text { power is distributed } \\
\text { unequally }\end{array}$} & $\begin{array}{l}\text { Less concentration of } \\
\text { authority, flat }\end{array}$ & $\begin{array}{l}\text { More concentration of } \\
\text { authority, tall }\end{array}$ & \multirow[t]{2}{*}{$40 / 80$} & \\
\hline & $\begin{array}{l}\text { organization pyramids, } \\
\text { subordinates expect to } \\
\text { be consulted }\end{array}$ & $\begin{array}{l}\text { organization pyramids, } \\
\text { subordinates expect to } \\
\text { be told }\end{array}$ & & 159 \\
\hline $\begin{array}{l}\text { Uncertainty avoidance: } \\
\text { extent to which } \\
\text { members of a culture are } \\
\text { comfortable or } \\
\text { uncomfortable in } \\
\text { unstructured situations }\end{array}$ & $\begin{array}{l}\text { Company rules should } \\
\text { not be broken, more } \\
\text { resistance to change, } \\
\text { suspicion of foreigners } \\
\text { as managers }\end{array}$ & $\begin{array}{l}\text { Company rules may be } \\
\text { broken, less resistance } \\
\text { to change, acceptance of } \\
\text { foreigners as managers }\end{array}$ & $46 / 30$ & \\
\hline $\begin{array}{l}\text { unstructured situations } \\
\text { Individualism and } \\
\text { collectivism: the degree } \\
\text { to which individuals } \\
\text { look after themselves or } \\
\text { are integrated into the } \\
\text { group }\end{array}$ & $\begin{array}{l}\text { Employee commitment } \\
\text { to organization low, } \\
\text { personal relationships } \\
\text { prevail over task and } \\
\text { company, less control } \\
\text { over job and working } \\
\text { conditions }\end{array}$ & $\begin{array}{l}\text { Employee commitment } \\
\text { to organization high, } \\
\text { task and company } \\
\text { prevail over personal } \\
\text { relationships, more } \\
\text { control over job and } \\
\text { working conditions }\end{array}$ & $91 / 20$ & \\
\hline $\begin{array}{l}\text { Masculinity and } \\
\text { femininity: the degree } \\
\text { "toughness" } \\
\text { "tenderness" within } \\
\text { a culture }\end{array}$ & $\begin{array}{l}\text { Work to live, managers } \\
\text { expected to use } \\
\text { intuition, managers hold } \\
\text { modest career } \\
\text { aspirations }\end{array}$ & $\begin{array}{l}\text { Live to work, managers } \\
\text { expected to be decisive, } \\
\text { managers have } \\
\text { ambitious career } \\
\text { aspirations }\end{array}$ & $62 / 66$ & \\
\hline $\begin{array}{l}\text { Long - v. short-term } \\
\text { orientation: The degree } \\
\text { to which members of a } \\
\text { culture delay } \\
\text { gratification of material, } \\
\text { social, and emotional } \\
\text { needs }\end{array}$ & $\begin{array}{l}\text { Quick results expected, } \\
\text { respect for traditions, } \\
\text { emphasis on bottom line }\end{array}$ & $\begin{array}{l}\text { Persistence and } \\
\text { perseverance, adapt } \\
\text { traditions to new } \\
\text { situations, building } \\
\text { of relationships and } \\
\text { market position }\end{array}$ & $29 / 118$ & $\begin{array}{l}\text { Table II. } \\
\text { hofstede's }\end{array}$ \\
\hline \multicolumn{4}{|c|}{ Source: Adapted from Hofstede (2001); ${ }^{a}$ www.geert-hofstede.com (accessed May 7, 2012) } & cultural dimensions \\
\hline
\end{tabular}

data collection techniques in both countries and the potentials and challenges of each. The data analysis and results section assesses the results of the analysis and identifies similarities and differences between the two countries. The discussion and conclusion section relates the results to the literature review and presents the conclusions of the research. The final section, relevance addresses the significance of the findings for logistics/supply-chain management practitioners, researchers, and teachers; and discusses the implications for logistics/supply-chain theory.

\section{Literature review}

A review of the literature has identified 11 studies that demonstrated a progression of thought and analysis regarding the Bowersox/Daugherty typology and provided a foundation for the research reported in this manuscript are reviewed in the following paragraphs. These 11 studies, and eight additional studies discussed earlier are summarized in Table III. 
IJLM

24,2

\section{0}

Table III.

Comparison of selected logistics strategy studies

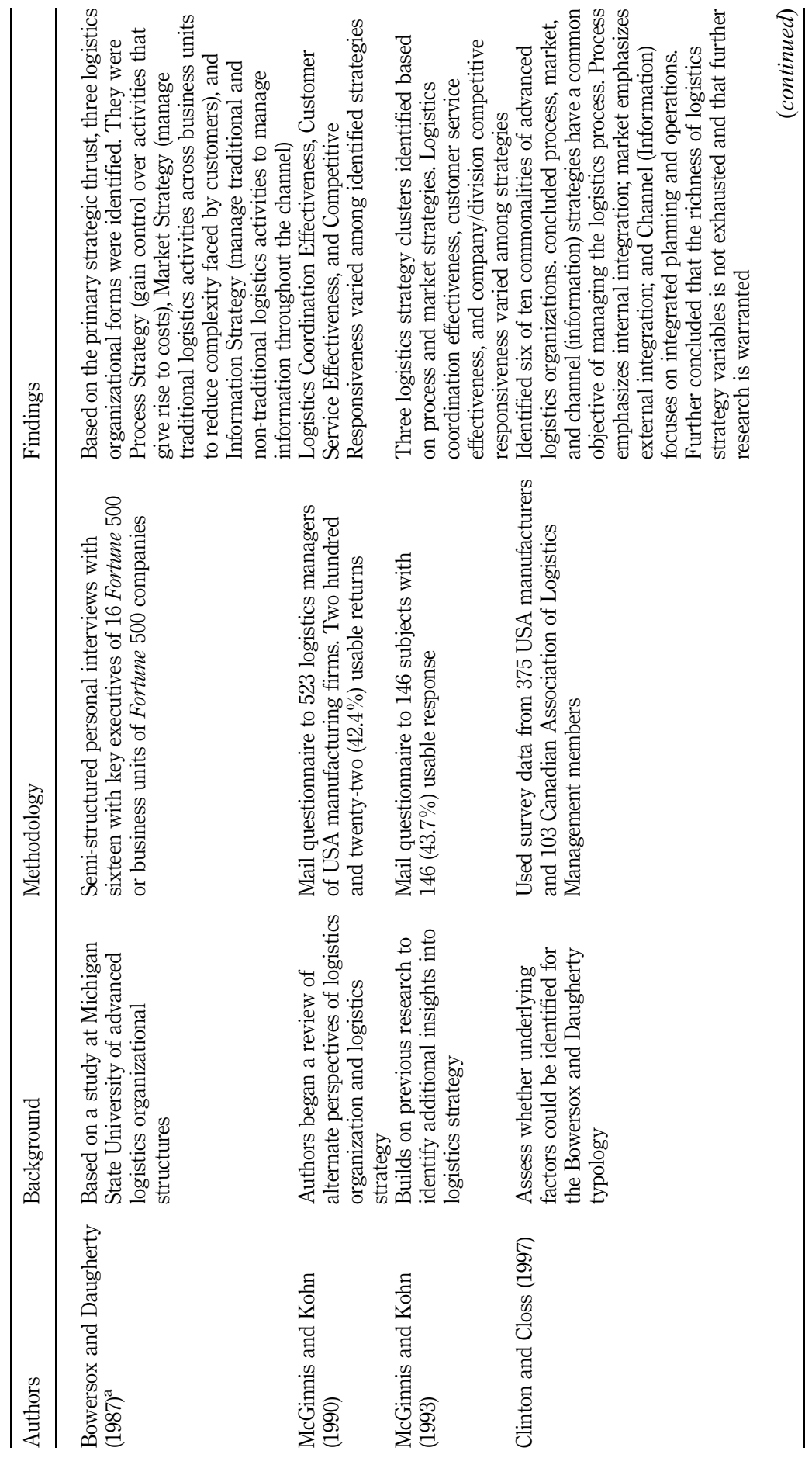




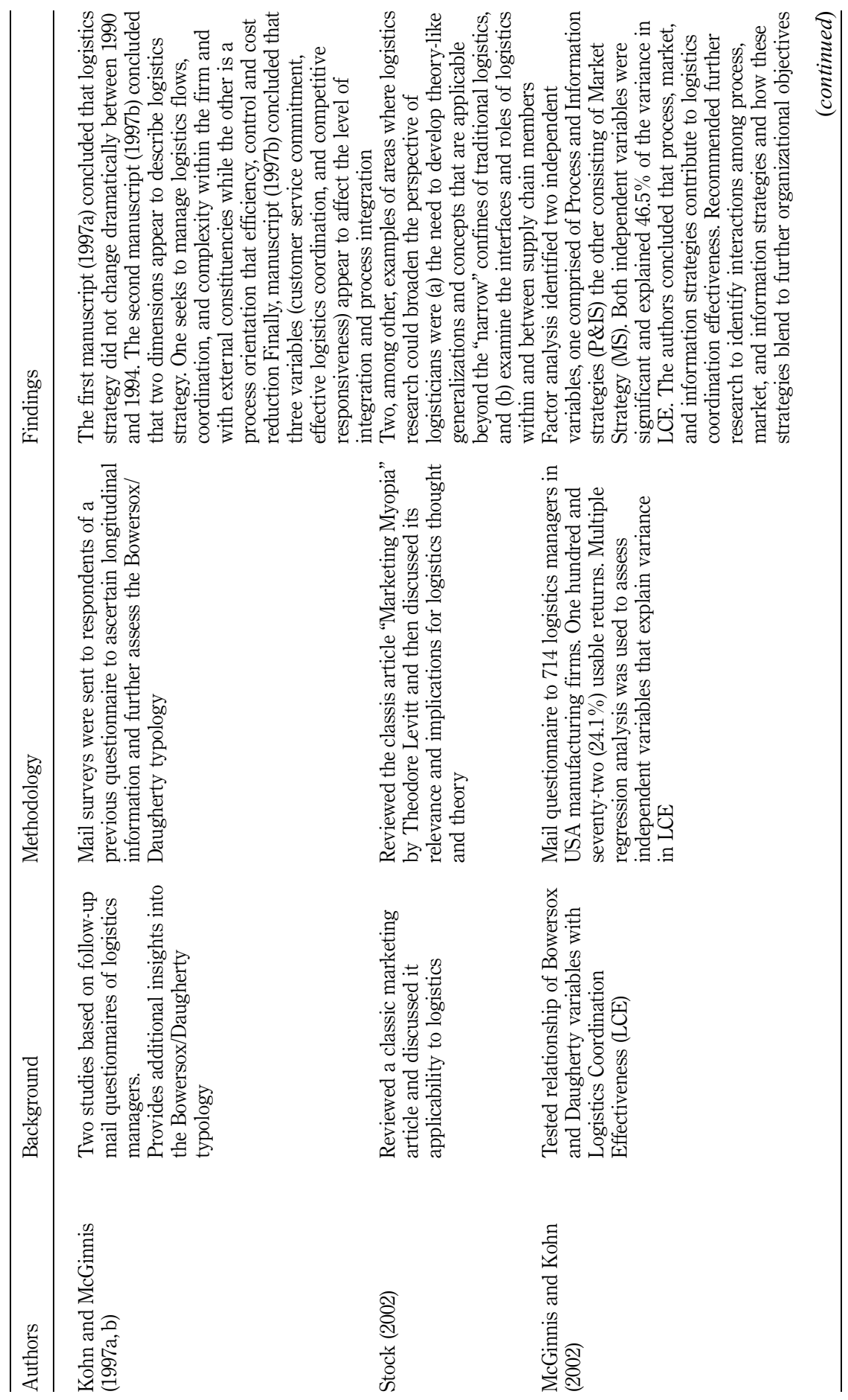

Logistic strategy and integration

161

Table III. 
IJLM

24,2

162

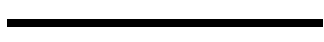

Table III.

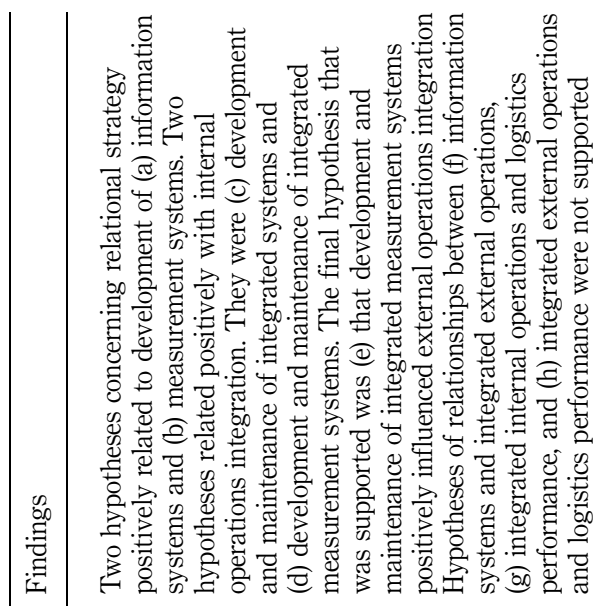

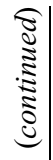

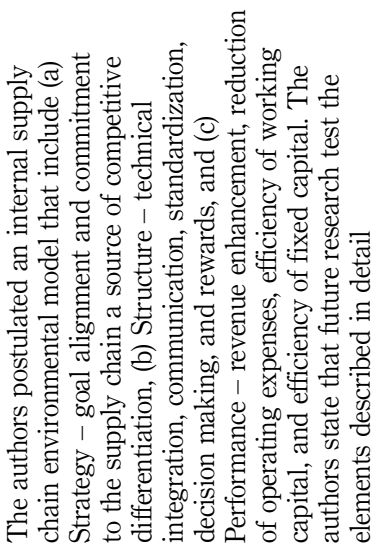

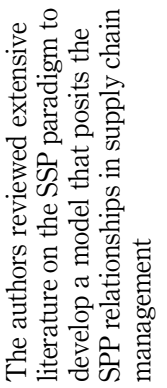

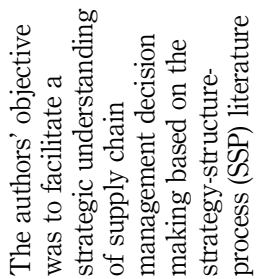




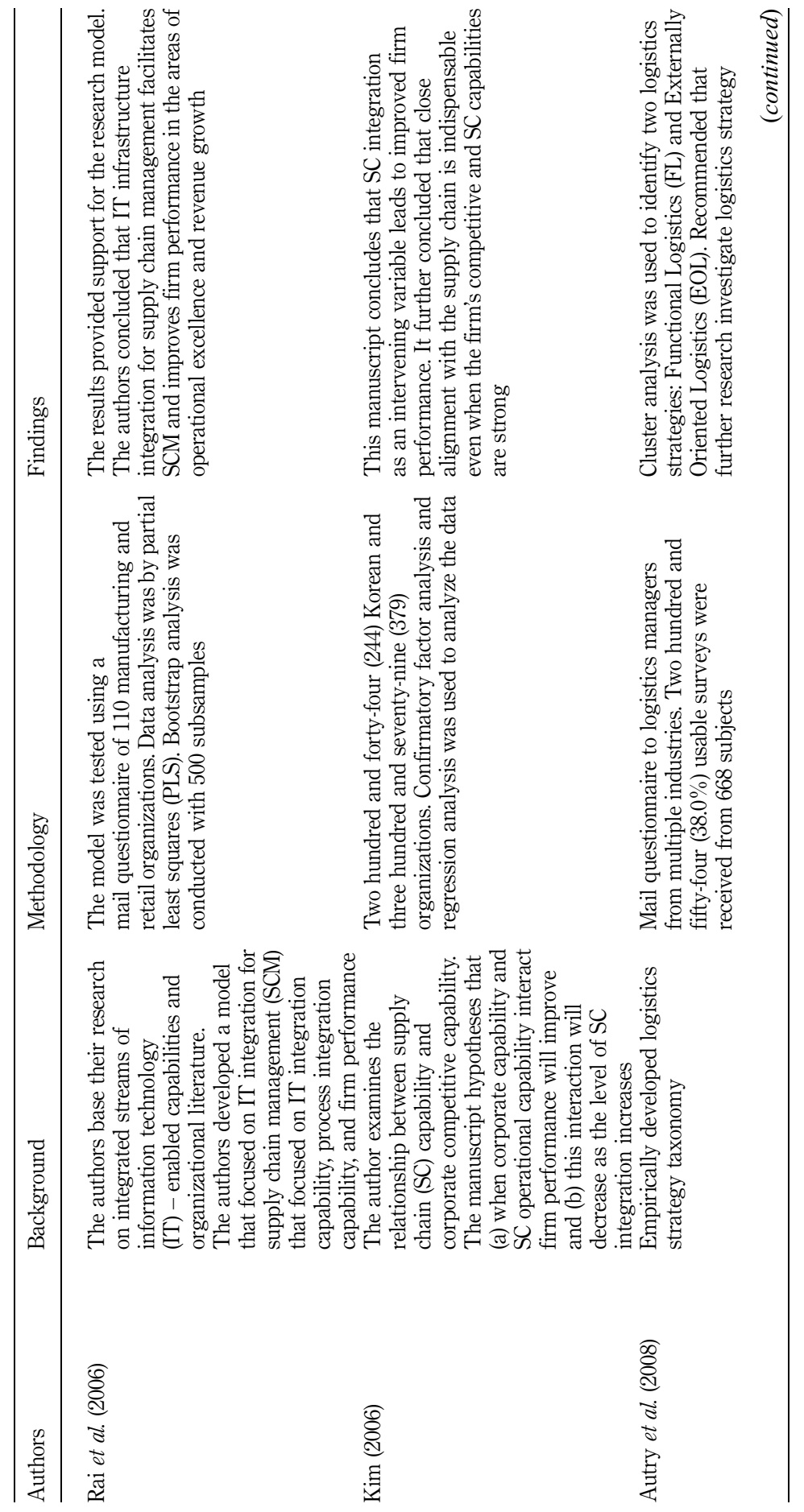

Logistic strategy and integration

163

尊,

क त्త

구을

졸

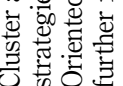

.

छ 들

击苟市

ษ

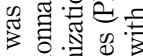

की

등

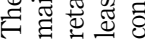

\section{ఫ}


IJLM
24,2

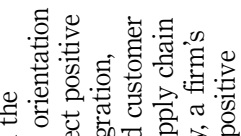

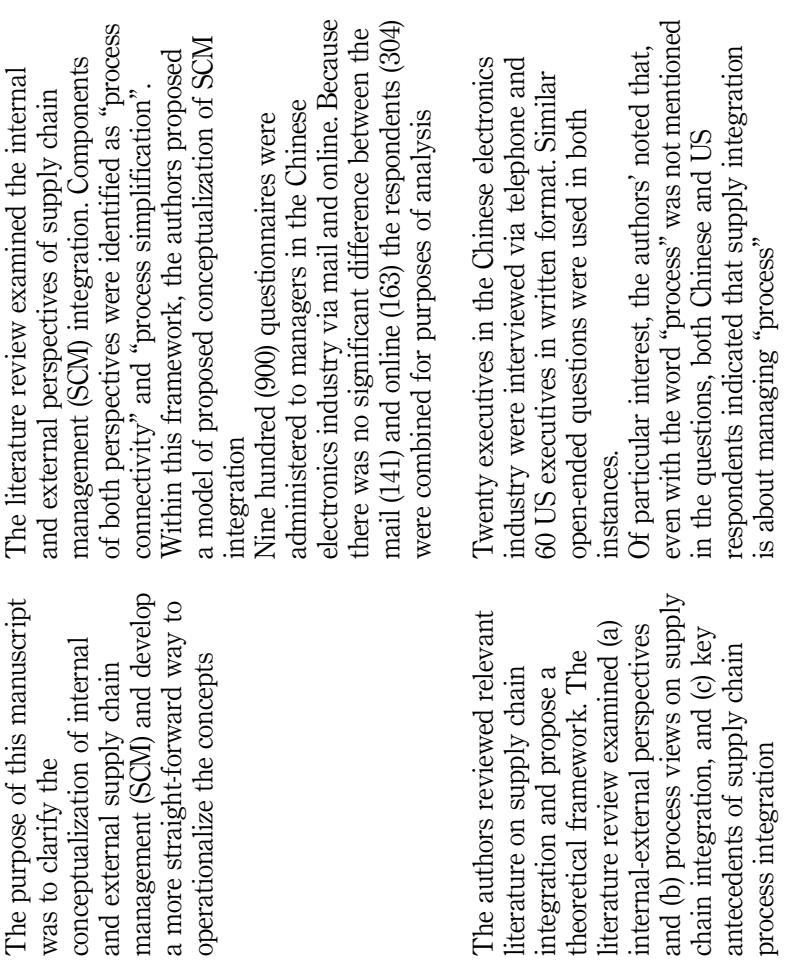

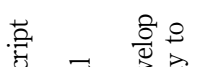

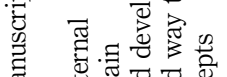

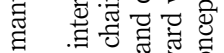

点

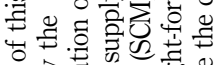

诺

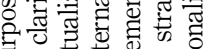

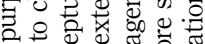

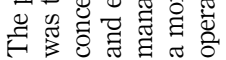

Table III.

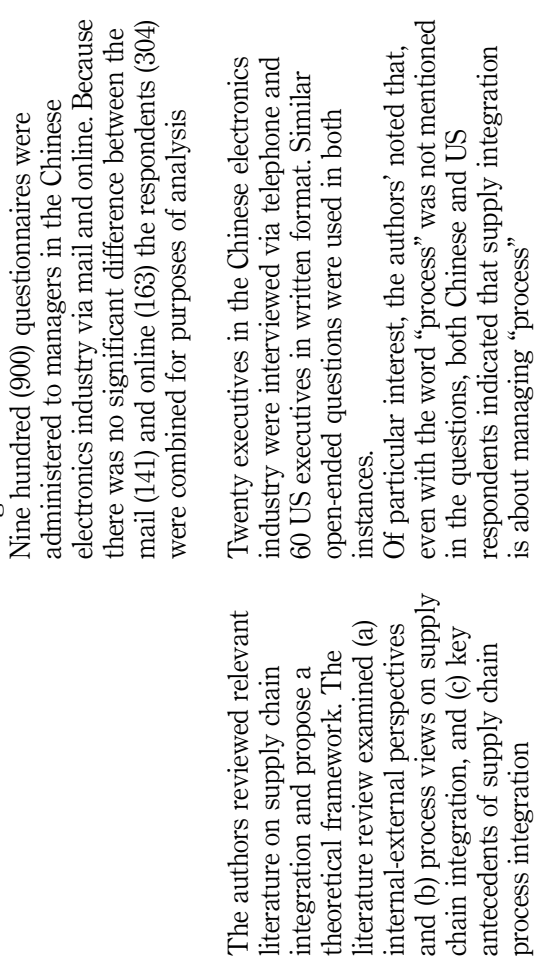

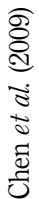




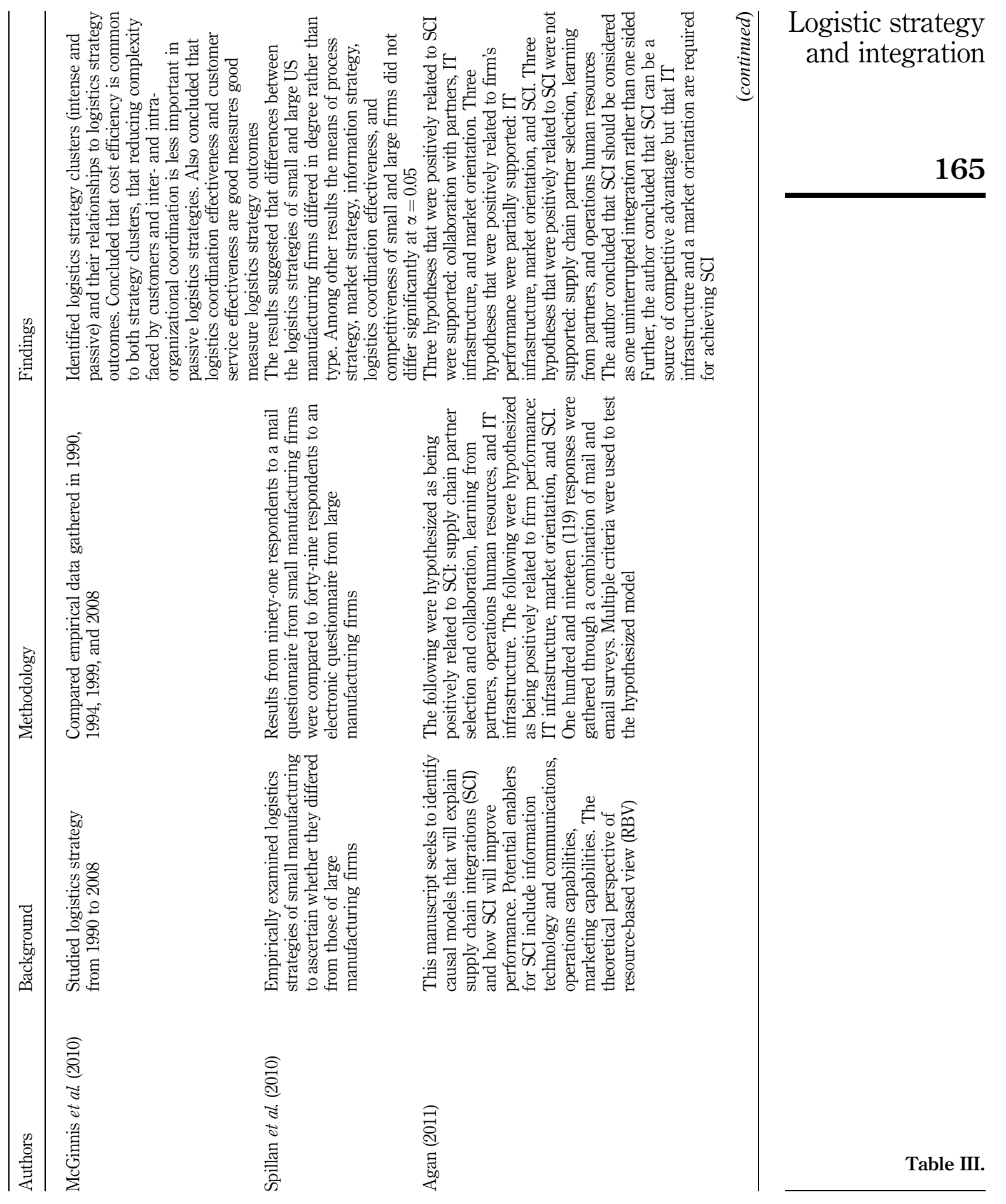


IJLM

24,2

166

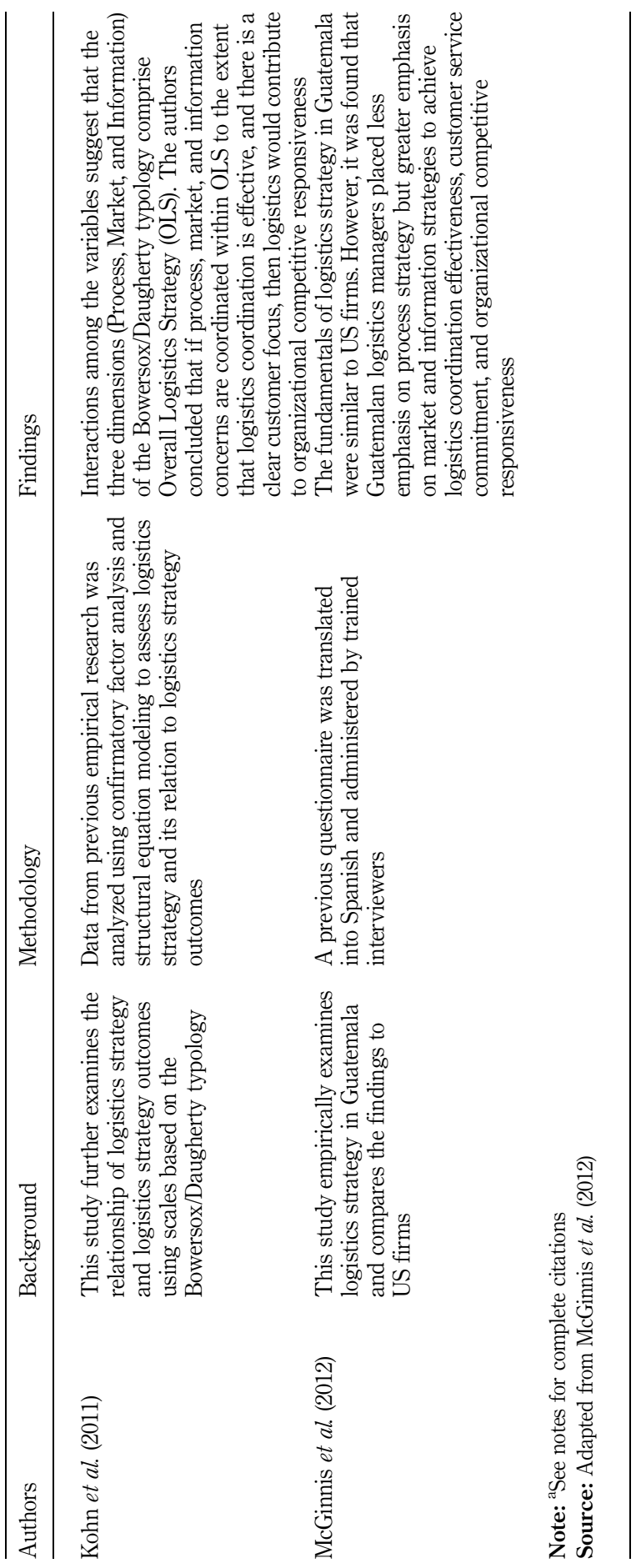

Table III. 
The original Bowersox and Daugherty (1987) work used personal and telephone interviews to identify three primary logistics thrusts namely process strategy, which stresses cost control; market strategy, which concentrates on the reduction of complexity customers' face; and information strategy, which centers on the coordination of information within the firm and throughout the channel. Within the same general time frame McGinnis and Kohn (1990) used mail questionnaires to identify three variables (LCE, CSE, and competitive responsiveness) that could be useful in the empirical study of logistics and logistics strategy. These three variables have been useful in subsequent research. All six variables are scales that have been replicated, appear to fit the construct name, have relevant levels of reliability, and are discussed in detail by McGinnis et al. (2010).

The studies summarized in this Table III used variables based on the Bowersox and Daugherty (1987), and some of them also used the three dimensions identified by McGinnis and Kohn (1990). McGinnis and Kohn (1993) identified logistics strategy clusters and determined that LCE, CSE, and company/division competitive responsiveness varied significantly among logistics strategies. Clinton and Closs (1997) found that process, market, and channel (information) strategies have a common objective in managing logistics processes, as opposed to the original Bowersox and Daugherty (1987) suggestion that advanced logistics organizations have a primary orientation of process, market, or information.

Kohn and McGinnis (1997a, b) conducted a follow-up study to assess whether the results from earlier work was static or dynamic. They found that logistics strategy did not change substantially between 1990 and 1994. Additionally, two strategies were identified. One was a blend of the Bowersox/Daugherty dimensions market and information and the other was primarily process. These findings were consistent with the previously cited work by Clinton and Closs (1997). A later study by McGinnis and Kohn (2002) identified two strategies, one was a combination of process and information items and the other was comprised solely of market items. Autry et al. (2008) used cluster analysis with Bowersox/Daugherty-based questionnaire items to identify two types of logistics, called functional logistics and externally oriented logistics. They recommended that further research be conducted to investigate logistics strategy. Taken together, the research reviewed in this paragraph suggests that, logistics strategy is not uni-dimensional. Rather, when using the dimensions of the Bowersox/Daugherty typology, logistics strategy is likely to be a blend of the three dimensions (process, market, and information) and that additional research may provide greater insight into the nature of logistics strategy.

McGinnis et al. (2010) compared the results of four sets of empirical data on logistics strategy $(1990,1994,1999$, and 2008) to assess whether changes over an eighteen-year period had changed substantially. One purpose of this research was to assess whether the variables, and their questionnaire items, were adequately stable for continuing research using earlier developed variables. A second purpose of this research was to ascertain whether there were any common themes in logistics strategy during the period studied. The results indicated that the variables were adequately stable for continuing research and that cost efficiency was common regardless of logistics strategy and that reducing the complexity customers faced (market strategy) and intraand inter-organizational coordination (information strategy) are important in intense strategies, but less important in passive strategies.

Previous logistics research had focussed on large organizations. Spillan et al. (2010) empirically compared logistics strategies in small and large US manufacturing firms. 
IJLM

24,2

168
They found that logistics strategies differed in degree rather than type. While some differences were noted, most variables did not differ between small and large firms at $\alpha=0.05$. Kohn et al. (2011) examined the interactions of the Daugherty/Bowersox variables (process, market, and information) and the earlier identified outcome variables (LCE, customer service commitment, and competitive responsiveness) using confirmative factor analysis and structural equation modeling. The results indicated that a blend of process, market, and information strategies resulted in OLS. Further, the results indicated that the components of OLS were well coordinated, and that logistics coordination is effective and there is a clear customer focus, then logistics strategy is likely to contribute to organizational competitive responsiveness.

McGinnis et al. (2012) empirically compared logistics strategies in Guatemala and the USA. They found that, despite substantial differences in demographics, economies, and cultures, Guatemalan logistics strategies were similar to US firm. Differences were modest. Guatemalan logistics managers placed less emphasis strategy and more emphasis on market and information strategies to achieve LCE, customer service commitment, and organizational competitive responsiveness.

After reviewing past research, the authors concluded the potential exists for further cross-cultural logistics strategy research. The authors identified China as a country that could provide further insights into cross-cultural issues in logistics strategy. As discussed earlier, both China and the USA are large economies with diverse histories, demographics, cultural values, and rates of economic development. Based on the previous research, the authors concluded that the Bowersox/Daugherty typology would be appropriate for a continuing program of studying logistics/supply-chain management in cross-cultural context.

\section{Research methodology}

Measures and questionnaire development

To conceptualize the factors of our research model, we used Likert scales adapted from McGinnis et al. (2010). The questionnaire was divided into three parts. In the first part, the overall logistic strategies of the companies were measured by three dimensions; process strategy, market strategy and information strategy. Respondents were asked to determine their level of agreement with three statements each for process, market, and information strategies for their company/division on a five point - type scale ( $1=$ definitely agree, $5=$ definitely disagree). In the second part of questionnaire respondents were asked to respond to three questions regarding LCE using similar Likert scale measures $(1=$ definitely agree, $5=$ definitely disagree $)$ as was done in the first part of the questionnaire. In the third part of the questionnaire, respondents were asked to respond to seven questions relating to customer service commitment (three questions) and company division competitiveness (four questions). Again, Likert scales were used.

\section{Data collection}

Data for the US sample were collected in 2008 using a four-page, 46-item questionnaire that was sent electronically to $n=905$ CSCMP members who worked for US manufacturing firms had managerial job titles in logistics, distribution or supply-chain management. One hundred and twenty-three were undeliverable for a net sample of 782 subjects. Fifty (6.4 percent) usable responses were returned after two follow-ups. After comparing means, standard deviations, and reliability coefficients for the nineteen items used in this analysis with results from three previous samples in 1990, 
1994, and 1999 it was concluded that the results from the 2008 sample were adequate for inclusion in this research for the purposes of comparing USA and Chinese results.

The Chinese data were gathered under the supervision of one of the co-authors that is faculty member at a Chinese university, and is fluent in Chinese and "American" English. This co-author translated the English language questionnaire into Chinese and then trained students on how to administer the questionnaire. The questionnaire was then administered by students to a random sample of wide variety of organizations, both large state-owned and small and medium enterprises (SMEs) located over a wide area of firms, mainly in northwest China. A total of 361 usable questionnaires were obtained.

The three independent variables and three dependent variables used in this research are presented as Table IV. Included in Table IV are the items for each variable and the scale reliabilities in USA and China. Previous research (Kohn and McGinnis, 1997b) has concluded that the six variables are valid when studying logistics strategy using logistics managers in manufacturing firms for subjects.

\section{Analysis and results}

The first step was to check the construct reliabilities for all three countries. Table IV shows comparative average construct reliabilities.

Although the reliability scores (especially in the Chinese data set) were below the suggested levels (0.70) in the literature, in general we can make a case that these scores are satisfactory for testing and validating the structure reported in (Kohn et al. (2011). $\alpha$ is not a good indicator of unidimentionality and low levels of $\alpha$ can be attributed to the sample homogeneity (Bernardi, 1994) and do not put the results in question. Usually 0.70 is desired but Schmitt (1996, p. 351) states that "[...] use of any cutoff value is shortsighted." Accordingly, when a measure has other desirable properties, the low $\alpha$ scores may not be a major impediment to its use (Schmitt, 1996). In addition, as coefficient values are relatively receptive to the number of items in the constructs, particularly when constructs have fewer than ten items, as in the case of this research, it is common to find coefficient $\alpha$ 's around 0.50 (Pallant, 2007). For instance, almost all alphas reported in Rojas-Méndez and Davies (2005) study was below the cutoff suggested in the literature. The scale items used in our study have been previously used in several studies in the literature; have considered having sufficient content validity (Kohn and McGinnis, 1997a) and possessing adequate levels of reliability. All constructs have been previously described and discussed by Keller et al. (2002). Previous studies that used these scales also reported low $\alpha$ scores (Kohn et al., 2011).

With the intention of evaluate whether the correlations among variables are suitable for factor analysis, we examined the Kaiser-Meyer-Olkin measure of sampling adequacy (KMO-MSA) (Kaiser, 1970). Table V shows the results for KMO tests for sampling adequacy and Bartlett's test for sphericity for the two data sets, USA and China as well as the mean scores for the constructs in all three countries. The value of KMO-MSA was 0.832 , for the US sample and 0.823 for the Chinese sample indicating the data were appropriate for factor analysis. All KMO results were above 0.50, which is the minimum cutoff for factor analysis. Additionally all levels of significance for Bartlett's test for sphericity is $<0.005$. KMO results along with the Bartlett results indicate the data is suitable for factor analysis. 
1. In my company/division, management emphasizes achieving maximum

2. A primary objective of logistics in my company/division is to gain control over activities that result in purchasing, manufacturing, and distribution costs

3. In my company/division, logistics facilitates the implementation of cost and inventory reducing concepts such as focused manufacturing and just-in-time materials procurement

Scale 2: Market strategy (MKTGSTR)

1. In my company/division, management emphasizes achieving coordinated physical distribution to customers served by several business units

2. A primary objective of logistics in my company/division is to reduce the complexity our customers face in doing business with us

3. In my company/division, logistics facilitates the coordination of several business units in order to provide competitive customer service

Scale 3: Information strategy (INFORSTR)

1. In my company/division, management emphasizes coordination and control of channel members (distributors, wholesalers, dealers, retailers) activities

2. A primary objective of logistics in my company/division is to manage information flows and inventory levels throughout the channel of distribution

3. In my company/division, logistics facilitates the management of information flows among channel members (distributors, wholesalers, dealers, retailers)

Logistics coordination effectiveness (LCE)

1. The need for closer coordination with suppliers, vendors, and other channel members has fostered better working relationships among departments within my company

2. In my company logistics planning is well coordinated with the overall strategic planning process

3. In my company/division logistics activities are coordinated effectively with customers, suppliers, and other channel members

Customer service effectiveness (CSE)

1. Achieving increased levels of customer service has resulted in increased emphasis on employee development and training

2. The customer service program in my company/division is effectively coordinated with other logistics activities

3. The customer service program in my company/division gives us a competitive edge relative to our competition

Company/division competitiveness (COMP)

1. My company/division responds quickly and effectively to changing customer

Table IV.

Scale items or supplier needs compared to our competitors

2. My company/division responds quickly and effectively to changing competitor strategies compared to our competitors

3. My company/division develops and markets new products quickly and effectively compared to our competitors

4. In most of its markets my company/division is a $(1=$ very strong competitor, $5=$ very weak competitor)

Note: ${ }^{a}$ Except for item $6.4,1=$ strongly agree, $2=$ agree, $3=$ neither agree nor disagree, $4=$ disagree, $5=$ strongly disagree

Source: ${ }^{\mathrm{b}}$ The US data are the 2008 data set reported in McGinnis et al. (2010) 


\begin{tabular}{|c|c|c|c|c|}
\hline Scales & $\mathrm{USA}^{\mathrm{a}}$ & China & $\begin{array}{c}\text { Significant } \\
\text { mean difference }\end{array}$ & $\begin{array}{l}\text { Logistic strategy } \\
\text { and integration }\end{array}$ \\
\hline \multicolumn{5}{|l|}{ Process strategy (PROCSTR) } \\
\hline$n$ & 50 & 361 & \multirow{4}{*}{ No } & \multirow{4}{*}{171} \\
\hline$\mu$ & 2.19 & 2.24 & & \\
\hline$\sigma$ & 0.660 & 0.600 & & \\
\hline \multicolumn{3}{|l|}{ Market strategy (MKTGSTR) } & & \\
\hline$n$ & 49 & 361 & & \\
\hline$\mu$ & 2.41 & 2.33 & & \\
\hline$\sigma$ & 0.968 & 0.668 & & \\
\hline \multicolumn{5}{|l|}{ Information strategy (INFORSTR) } \\
\hline$n$ & 49 & 361 & \multirow{3}{*}{ Yes } & \\
\hline$\mu$ & 2.85 & 2.31 & & \\
\hline$\sigma$ & 0.758 & 0.614 & & \\
\hline \multicolumn{5}{|l|}{ Logistics coordination effectiveness (LCE) } \\
\hline$n$ & 50 & 361 & \multirow{3}{*}{ Yes } & \\
\hline$\mu$ & 2.58 & 2.31 & & \\
\hline$\sigma$ & 0.609 & 0.674 & & \\
\hline \multicolumn{5}{|l|}{ Customer service commitment (CSC) } \\
\hline$n$ & 50 & 361 & \multirow{3}{*}{ Yes } & \\
\hline$\mu$ & 2.63 & 2.33 & & \\
\hline$\sigma$ & 0.772 & 0.665 & & \\
\hline \multicolumn{5}{|c|}{ Company/division competitiveness (COMP) } \\
\hline$n$ & 48 & 361 & \multirow{3}{*}{ No } & \\
\hline$\mu$ & 2.42 & 2.37 & & \\
\hline$\sigma$ & 0.659 & 0.679 & & \\
\hline KMO measure of sampling adequacy & 0.832 & 0.823 & & \\
\hline Bartlett's test of sphericity & 0.000 & 0.000 & & $\begin{array}{l}\text { Table V. } \\
\text { Comparison of means }\end{array}$ \\
\hline \multicolumn{4}{|c|}{$\begin{array}{l}\text { Notes: Scales: } 1=\text { strongly agree, } 2=\text { agree, } 3=\text { neither agree nor disagree, } 4=\text { disagree, } 5=\text { strongly } \\
\text { disagree. b Scale scores }=\text { (Sum of item scores of items in that scale)/(number of items); ***statistical } \\
\text { significance at } p<0.05\end{array}$} & $\begin{array}{l}\text { of scale scores: large } \\
\text { USA manufacturing } \\
\text { firms and Chinese }\end{array}$ \\
\hline \multicolumn{4}{|c|}{ Source: ${ }^{a}$ The USA data is the 2008 data set reported in McGinnis et al. (2010) } & manufacturing firms \\
\hline
\end{tabular}

\section{Confirmatory factor analysis}

To confirm the underlying factor structure, the authors conducted CFA on both data sets using AMOS. We assessed the goodness of fit of the models using various fit indices testified in previous studies, including the $\chi^{2}$ statistic, normed fit index (NFI), non-normed fit index, (NNFI), comparative fit index (CFI), goodness-of-fit index (GFI); standardized root mean, square residual (SRMR); and root mean square error of approximation (RMSEA). The two-step approach suggested by Anderson and Gerbing (1988) was used to first examine the measurement model and then the structural model. In the measurement model, the hypothesized relationship between the nine logistic strategic orientations and the three first-order factors were examined to understand how well the relationships fit the data. In the structural model, we examined the relationship between the three first-order factors (PROCSTR, MKTGSTR, and INFORSTR). The findings supported the underlying factor structure of the 19 items with correlated factors.

The results of the estimation of the first-order factor model revealed very strong results for all data sets used as indicated by several different measures $\left(\chi_{\text {USA }}^{2}=31.058\right.$, $p<0.363$ and $\left.\chi_{\text {China }}^{2}=25.808, p<0.095\right)$ and they were insignificant indicating a very 
IJLM

24,2

172

good model fit. The figures of GFI and CFI, were all larger than or equal for all three countries $\left(\mathrm{GFI}_{\mathrm{USA}}=0.962 ; \mathrm{CFI}_{\mathrm{USA}}=0.970 ; \mathrm{GFI}_{\text {China }}=0.985 ; \mathrm{CFI}_{\text {China }}=0.995\right)$.

The normalized chi-square $\left(\chi^{2} /\right.$ degrees of freedom) of the CFA model was smaller than the recommended value of 3.0, the RMR was smaller than 0.05 , and the RMSEAs were small $\left(\right.$ RMSEA $_{U S A}=0.049$; RMSEA China $\left.=0.014\right)$. Accordingly, the results showed that all loadings in the model were significant, leading us to conclude that the relationships between the items and latent factors were confirmed by the data sets obtained from the two countries.

The last step in this process to confirm the underlying structure of the model was to evaluate the relationship between the three first-order factors and a second-order factor named "overall logistic strategy." Our purpose here is to understand how the three factors contributed to an overall single construct (OLS). The results of the second-order confirmatory factor analyses for both data sets showed very good fit indices $\left(\chi_{\mathrm{USA}}^{2}=31.058 ; \mathrm{GFI}_{\mathrm{USA}}=0.962 ; \mathrm{CFI}_{\mathrm{USA}}=0.970 ; \mathrm{RMSEA}_{\mathrm{USA}}=0.049 ; \chi_{\text {China }}^{2}=25.81\right.$; $\left.\mathrm{GFI}_{\text {China }}=0.985 ; \mathrm{CFI}_{\text {China }}=0.985 ; \mathrm{RMSEA}_{\text {China }}=0.014\right)$.

\section{Structural models}

The structural model was used to test the hypotheses of all six factors tested in the measurement model. The hypothesized structural models for both data sets are shown in Figure 2. Inspection of Figure 2 revealed that the all linkages were significant and the directions of relationships were as hypothesized for the US and China data sets. Figure 2 also displays standardized coefficients for the linkages, $R^{2}$ values for the variables, as well as correlation coefficients between two sets of measurement variables. Finally, the values for $\chi^{2}$, GFI, CFI, and RMSEA values all point to good model fit in both data sets.

A final analysis conducted in this study sought to ascertain whether logistics strategies were homogenous (or heterogeneous) for the US and Chinese respondents. To assess this issue SPSS 16.0's two-step cluster was used to group the independent variables (PROCSTR, MKTGSTR, and INFORSTR) into "strategy clusters." As shown in Table VI, both sets of respondents grouped into two strategy clusters. The clusters with lower values for the independent values were named "intense logistics strategy" and the other cluster named "passive logistics strategy."

Inspection of Table VI provides an array of insights into comparative USA and Chinese logistics strategies, as indicated by the respondents. First, both sets of respondents were grouped into two strategy clusters. However, 71.4 percent of the USA respondents grouped into "intense logistics strategy" while 49.9 percent of Chinese respondents grouped into that strategy cluster. Conversely, 28.6 percent of USA respondents grouped into "passive logistics strategy" while 50.1 percent of Chinese respondents grouped into that strategy cluster.

Further examination of the independent variables (PROCSTR, MKTGSTR, INFORSTR) suggest that, while both USA and Chinese respondents identified as having intense logistics strategies, Chinese respondents place relatively greater importance on INFORSTR (management of logistics coordination, control, and information flows) than do USA respondents. In addition Chinese respondents, in both intense and passive logistics strategies, place greater importance on LCE (coordination of logistics activities with customers, suppliers, other channel members, and the strategic planning process) and CSE (increased levels of customer service, coordination of customer service with other logistics activities, and effective coordination with customers, suppliers, and other channel members). Finally, an examination of COMP 


\begin{tabular}{|c|c|c|c|}
\hline \multicolumn{2}{|c|}{ USA $(n=49)$} & \multicolumn{2}{|c|}{ China $(n=361)$} \\
\hline $\begin{array}{c}\text { Intense logistics } \\
\text { strategy } \\
(n=35,71.4 \%)\end{array}$ & $\begin{array}{c}\text { Passive logistics } \\
\text { strategy } \\
(n=14,28.6 \%)\end{array}$ & $\begin{array}{c}\text { Intense logistic } \\
\text { strategy } \\
(n=180,49.9 \%)\end{array}$ & $\begin{array}{c}\text { Passive logistics } \\
\text { strategy } \\
(n=181,50.1 \%)\end{array}$ \\
\hline
\end{tabular}

PROCSTR

$\mu$
$\sigma$

MKTGSTR

$\mu$

$\sigma$

INFORSTR

$\mu$

LCE

$\mu$

$\sigma$

CSE

$\mu$

$\sigma$

COMP

$\mu$

Notes: Scales: $1=$ strongly agree, $2=$ agree, $3=$ neither agree nor disagree, $4=$ disagree, $5=$ strongly

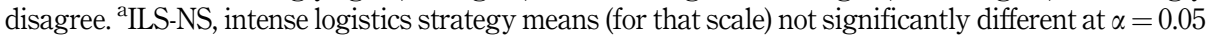
between US and Chinese data. For example, the means for PROCSTR for the US and Chinese respondents with intense logistics strategies were not significantly different, $\alpha=0.05$. However, the means for PROCSTR for US and Chinese respondents with passive logistics strategies were

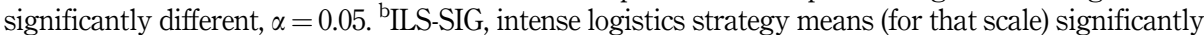
different at $\alpha=0.05$ between US and Chinese data. 'PLS-NS, passive logistics strategy means (for that scale) not significantly different at $\alpha=0.05$ between US and Chinese data. ${ }^{\mathrm{d}} \mathrm{PLS}-\mathrm{SIG}$, passive logistics strategy means (for that scale) significantly different at $\alpha=0.05$ between US and Chinese data $1.874^{\text {aILS-NS }}$

0.408

$1.952^{\text {bILS-SIG }}$

0.400

$2.072^{\text {bILSSIG }}$

0.547

$2.078^{\text {bILS-SIG }}$

0.601

$2.163^{\text {aILS-NS }}$

0.638
2.576
0.571

$2.786^{\text {dPLS-SIG }}$

0.551

$2.672^{\mathrm{dPLS}-S I G}$

0.578

$2.558^{\mathrm{d} P L S-S I G}$

0.650

$2.682^{\text {dPLS.SIG }}$

0.601

$2.572^{\text {cPLS-NS }}$

0.659
Logistic strategy and integration

173

Table VI.

Comparison of cluster analyses results of logistics strategies: national sample of large usa manufacturing firms versus Chinese manufacturing firms

(company division responsiveness to changing customer and supplier needs, changing competitor strategies, quickly developing and marketing new products, and perceived competitiveness) reveals that USA and Chinese respondents (in both intense and passive logistics strategies) view their organization's competitiveness similarly.

Our study findings show that given the Bowersox/Daugherty dimensions of logistics strategy are invariant across the two cultures/countries studied and that the measures of logistics strategy assessed by three dimensions validated in both the USA and China. Furthermore, these results suggest that the assumed links between logistics strategy and organizational competitiveness also hold in two the countries. These results indicate that OLS, which is comprised of process, market, and information dimensions, does impact perceived organizational competiveness both in the USA and China.

As shown in Figures 1 and 2, the models for logistics strategy and logistics strategic outcomes for China and the USA respondents indicate a high level of similarity. This observation is not in conflict with the findings of Chen et al. (2009b) and Chen et al. (2009a). OLS is comprised of Process Strategy (PROCSTR), Market Strategy (MKTGSTR), and Information Strategy (INFORSTR). Examination of Figure 2 
IJLM
24,2

174

Figure 1.

First-order confirmatory factor analysis for overall logistics strategy
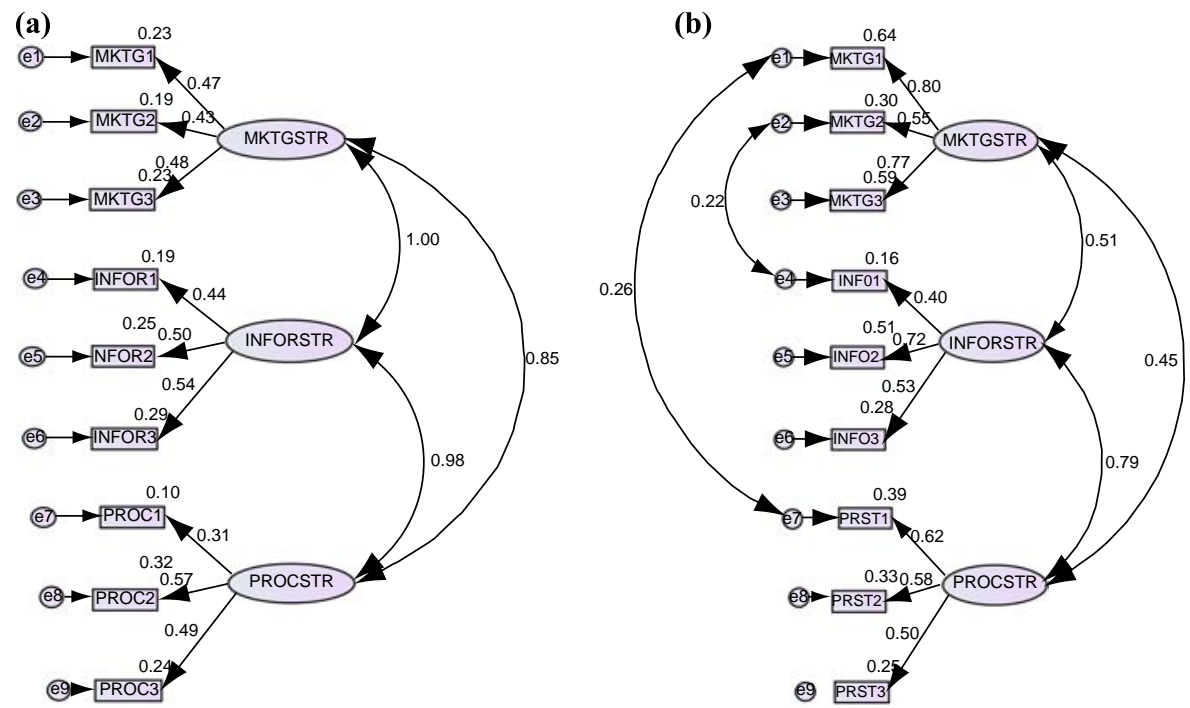

Notes: (a) Chinese data: $\chi^{2}=25.808, p=0.363, \mathrm{CFI}=0.995$, GFI $=0.985$, RMSEA $=0.014$; (b) US data: $\chi^{2}=31.058, p=0.095, \mathrm{CFI}=0.970, \mathrm{GFI}=0.962, \mathrm{RMSEA}=0.049$

reveals that OLS, when combined with LCE and CSE, contributes to perceived organizational competitiveness. These findings are especially interesting in that, while both China and the USA are large and have globally competitive economies, the histories, cultures, demographics characteristics, and systems of government are dissimilar. This suggests that the Bowersox/Daugherty model is applicable and validated across two of the largest economies of the world, despite significant differences between the cultural environments in two countries.

Examination of Table VI further reveals that a cluster analysis of the Chinese and USA data results in two different overall logistics strategies. They are "intense logistics strategies" and "passive logistics strategies." In each instance intense logistics strategies are associated with greater emphasis (a lower number indicates stronger agreement, according to the scales used) on the three components of OLS (process, market, and information strategies) and stronger outcomes in LCE, CSE, and COMP.

Closer examination of Table VI does reveal some differences between the USA and Chinese respondents. First, a higher percentage (71.4 percent) of USA respondents were classified as having intense logistics strategies while a lower percentage (49.9 percent) of Chinese respondents were classified as having intense logistics strategies. This suggests three possibilities. One is that Chinese logistics/supply-chain management is less sophisticated regarding the potential role of logistics strategy in achieving the organization's objectives. The second is that the competitive environment that Chinese logistics/supply-chain managers are less demanding than that faced by USA logistics/supply-chain managers. Third, it is possible that patterns of channel relationships are clearly defined to the extent that there it is less importance in placing a high priority on OLS in many Chinese organizations. Finally, a fourth possibility for less emphasis on logistics strategy in about half of the Chinese respondents is that other considerations are more important to the organization's competitive advantage. Such other considerations could be costs, capacity, and design capabilities, the 
(a)

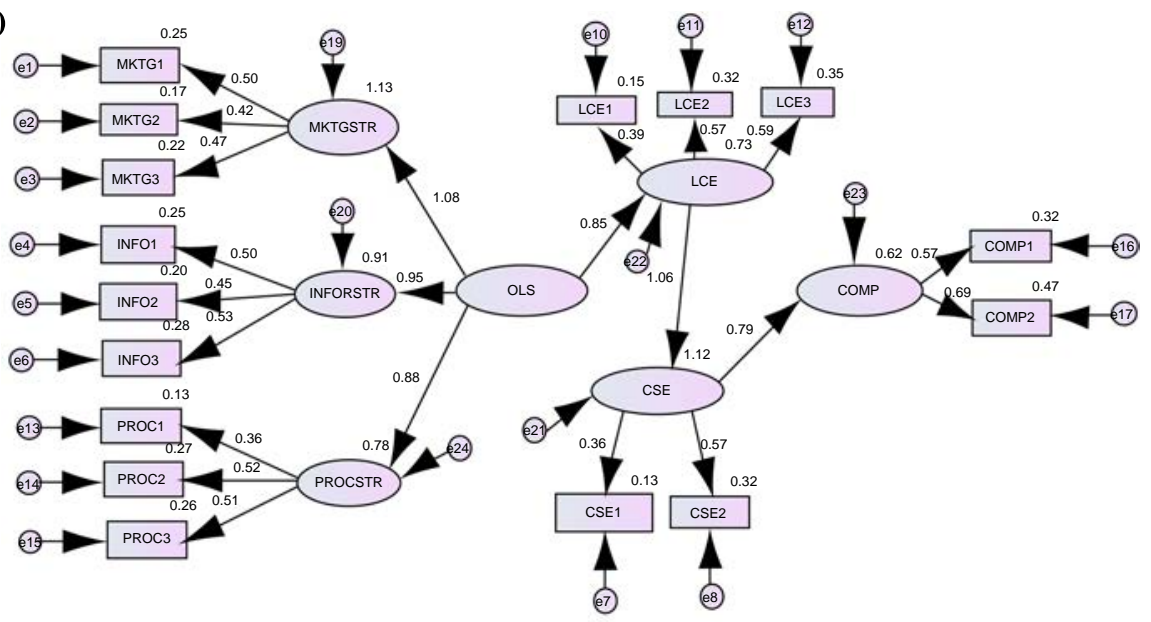

Logistic strategy and integration

(b)

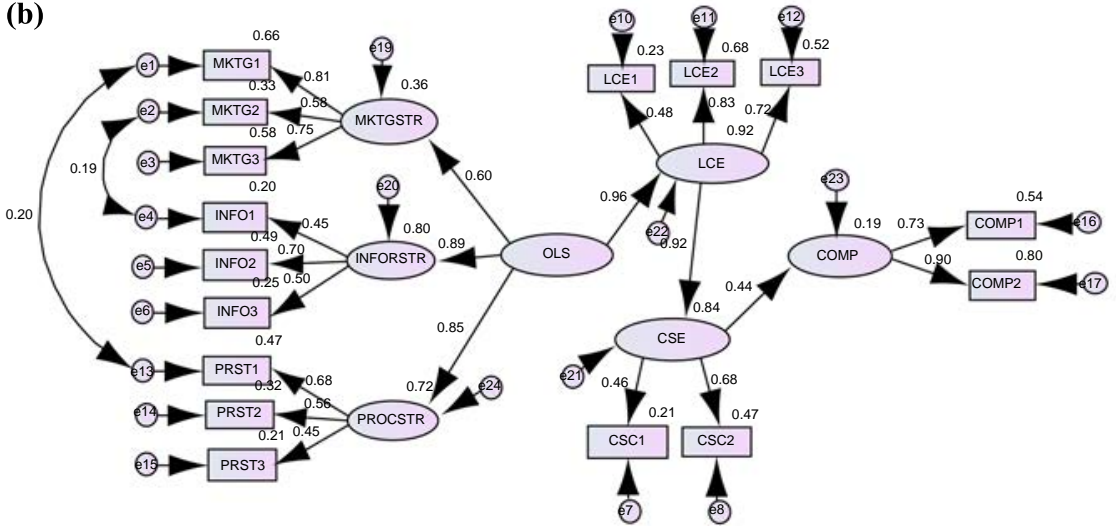

Notes: (a) Chinese data: $\chi^{2}=154.474, p$-value $=0.000, \mathrm{GFI}=0.949, \mathrm{CFI}=0.936, \mathrm{RMSEA}=0.040$; (b) US data: $\chi^{2}=125.971, p$-value $=0.022, \mathrm{GFI}=0.916, \mathrm{CFI}=0.960, \mathrm{RMSEA}=0.043$

Figure 2. Sem for overall logistics strategy and competitiveness

existences of long-term agreements with suppliers and/or customers, and longer lead times due to longer supply and customer channels.

Overall, the results reported in this manuscript suggest that the Bowersox/ Daugherty provide a strong framework for studying and explaining logistics/supplychain management in two large, dissimilar, economies. In other words, this study validates the dimensionality of the Bowersox/Daugherty measurement model for overall logistic strategy in a cross-cultural environment. Moreover, this study also confirms the relationships identified in the structural model with respect to the relationship among OLS, LCE and CSE, and perceived organizational competitiveness.

\section{Relevance and implications}

The research reported in this manuscript suggests that the fundamentals of the US and Chinese logistics strategies are similar. In addition, the results indicate that the 
IJLM

24,2

176
Bowersox/Daugherty typology is an appropriate typology for studying logistics/ supply-chain management strategy across two large but dissimilar cultures. These results should provide some comfort to trainers/faculty teaching logistics/supply-chain management to cross-cultural audiences. While there some differences, the framework of logistics/supply-chain management appears to be independent of culture. This finding is not inconsistent with the findings of Chen et al. (2009a) and McGinnis et al. (2012).

While the fundamentals of logistics strategy, as shown in Figures 1 and 2 are similar, closer examination of Table VI provides some insights into differences in the emphasis of logistics between the USA and China. As shown in Table VI, the percentage of respondents with "intense" logistics strategies was 71.4 and 49.9 percent, and the percentage of respondents with "passive" logistics strategies was 28.6 and 50.1 percent for US and Chinese respondents, respectively. Whether these findings suggest that US logistics strategies are "better" than Chinese logistics strategies is speculative. Possible reasons why a higher percentage of US logistics strategies are "intense" while a higher percentage of Chinese logistics strategies are "passive" may be due to the competitive nature of the industries in the two economies. For example, if US logistics/ supply-chain managers face competitive markets where logistics/supply-chain management is a source of differentiation then the greater emphasis on "intense" strategies would be appropriate. On the other hand, if Chinese logistics/supply-chain managers participate in less competitive markets, due to a higher percentage of export activity that is prescribed by foreign buyers, then the greater presence of "passive" strategies would be appropriate.

A second possible explanation for the differences in the level of "intense/passive" logistics strategies between the USA and China could be the extent of coordination between buyers and sellers. For example, if the members of a supply chain or central planning then the appropriate level of logistics strategy might relatively "passive."

Finally, an examination of Table II indicates that Chinese society is high on power distance, places greater emphasis on uncertainty avoidance, and is more collective than the USA. These characteristics suggest that logistics/supply-chain management strategies that are "passive" would be more consistent with the Chinese culture. Conversely, the US culture is lower on power distance, is less likely to avoid uncertainty, and is more individualistic. As a result the greater competitiveness within the US culture may favor "intensive" logistics/supply-chain management strategies.

Whether Chinese logistics/supply-chain management strategies would be more likely to be "intense" in the US' competitive environment is open to speculation. The authors' suspicion is that, based on the success of Japanese and Korean (countries with Hofstede cultural values differ from the USA) firms in US electronics and automotive markets, Chinese firms would be capable of adapting to the competitive nature of US markets and adapting "intense" logistics/supply-chain management strategies needed to compete.

For practitioners, these findings suggest that the fundamentals of logistics/supply management do not vary greatly in different cultures. This does not suggest that other issues, such as local custom, negotiation approaches, and the structure of agreements, will be similar to the extent that logistics/supply-chain management appears to be. Finally, those conducting comparative research into logistics/supply management should find that identifying subjects and conducting research requires the collaboration of researchers in the subject country. Further, American practitioner 
should not assume that the strategies that are applicable to Chinese logistics/supplychain managers in China would not necessarily be less "intense" and more "passive" than American logistics strategies as Chinese firms become more active in US markets. The rationale for this statement is that the Japanese and South Koreans have adapted in US markets and compete with domestic US firms in logistics and supplychain management in additions to other competitive dimensions.

\section{Suggestions for future research}

This study has a part of series of studies exploring the practices of logistics/supplychain management in other countries/cultures from a perspective of uncovering their impact on customer service and organizational competitive responsiveness. Further research into logistics and supply-chain management may benefit from expanding the understanding of logistics/supply-chain management decision making by including antecedents and moderating factors (such as competition, market turbulence, and differences in business environment) into the design. In addition to further study of logistics/supply-chain management in other nations/cultures, additional insight could be gained by examining the relevance of the Bowersox/ Daugherty typology to nonmanufacturing industries including retailing, healthcare, financial services, transportation firms, and food service. These industries may provide a different perspective on the process, market, and information strategy in different environments. Finally, future studies should try to synthesize the accumulated knowledge generated in these cross national studies into a more inclusive framework that provides a conceptual roadmap on the impact of logistics/ supply-chain management strategies on critical organizational success factors such as global competitiveness and profitability. An additional area of cross-cultural logistics/ supply-chain management strategy would be to compare logistics strategies of countries in their home markets v. their strategies in their foreign markets. The authors suspect that logistics/supply-chain management strategies will often vary between the home country and its foreign markets.

Next, approaches to the study of cross-cultural logistics/supply-chain management logistics may also benefit from the application of SSP approaches similar to those discussed earlier in this manuscript. Finally, the results from the literature reviewed, together with the findings of the research reported in this manuscript, may contribute the development of theory-like generalizations and a better understanding of the roles of logistics and supply-chain management as suggested by Stock (2002).

\section{References}

Agan, Y. (2011), "Impact operations, marketing, and information technology capabilities on supply chain integration", Journal of Economic and Social Research, Vol. 13 No. 1, pp. 27-56.

Anderson, J.C. and Gerbing, D.W. (1998), "Structural equation modeling in practice: a review and recommended two-step approach", Psychological Bulletin, Vol. 103, pp. 411-423.

Autry, C.W., Zacharia, Z.G. and Lamb, C.W. (2008), "A logistics strategy taxonomy", Journal of Business Logistics, Vol. 29 No. 2, pp. 27-51.

Bernardi, R.A. (1994), "Validating research results when Cronbach's alpha is below 0.70: a methodological procedure", Educational and Psychological Measurement, Vol. 54 No. 3, pp. 766-775.

Bowersox, D.J. and Daugherty, P.J. (1987), "Emerging patterns of logistical organization”, Journal of Business Logistics, Vol. 8 No. 1, pp. 46-60.
Logistic strategy and integration

177 
IJLM

24,2

\section{8}

Carter, J.R., Pearson, J.N. and Peng, L. (1997), "Logistics barriers to international operations: the case of the people's republic of China", Journal of Business Logistics, Vol. 18 No. 2, pp. 129-135.

Chen, H., Daugherty, P.J. and Landry, T.D. (2009), "Supply chain process integration: a theoretical framework", Journal of Business Logistics, Vol. 30 No. 2, pp. 27-46.

Chen, H., Daugherty, P.J. and Roath, A.R. (2009), "Defining and operationalizing supply chain integration", Journal of Business Logistics, Vol. 30 No. 1, pp. 63-84.

Clinton, S.R. and Closs, D.J. (1997), "Logistics strategy: doe it exist?", Journal of Business Logistics, Vol. 18 No. 1, pp. 19-44.

Defee, C.C. and Stank, T.P. (2005), “Applying the strategy-structure-performance paradigm to the supply chain environment”, International Journal of Logistics Management, Vol. 16 No. 1 , pp. 28-50.

Hofstede, G. (2001), Culture Consequences, 2nd ed., Sage Publications, Thousand Oaks, CA.

Jiang, B. and Prater, E. (2002), "Distribution and logistics development in China: the revolution has begun”, International Journal of Physical Distribution \& Logistics Management, Vol. 32 No. 9, pp. 783-798.

Kaiser, H.F. (1970), “A second generation little”, Psychometrica, Vol. 35 No. 4, pp. 401-415.

Kam, B.H., Tsahuridu, E.E. and Ding, M.J. (2010), "Does human resource management contribute to the development of logistics and supply chain capabilities? An empirical study of logistics service providers in China", Research and Practice in Human Resource Management, Vol. 18 No. 2, pp. 15-34.

Kearney, A.T. (2010), China 2015: Transportation and Logistics Strategies, Marketing and Communication Consultant, Chicago, IL.

Keller, S.B., Savitskie, K., Stank, T.P., Lynch, D.F. and Ellinger, A.E. (2002), "A summary and analysis of multi-item scales used in logistics research", Journal of Business Logistics, Vol. 23 No. 2, pp. 83-119.

Kim, S.W. (2006), "The effect of supply chain integration on the alignment between corporate competitive capability and supply chain operational capability", International Journal of Operations \& Production Management, Vol. 26 No. 10, pp. 1084-1107.

Kohn, J.W. and McGinnis, M.A. (1997a), "Logistics strategy: a longitudinal study", Journal of Business Logistics, Vol. 18 No. 2, pp. 1-14.

Kohn, J.W. and McGinnis, M.A. (1997b), “Advanced logistics organization structures: revisited”, Journal of Business Logistics, Vol. 18 No. 2, pp. 147-162.

Kohn, J.W., McGinnis, M.A. and Kara, A. (2011), "A structural equation model assessment of logistics strategy", The International Journal of Logistics Management, Vol. 22 No. 3, pp. 284-305.

Luo, W., Van Hoek, R.I. and Ross, H.H. (2001), "Cross-cultural logistics research: a literature review and propositions", International Journal of Logistics Research and Applications, Vol. 4 No. 1, pp. 57-78.

McGinnis, M.A. and Kohn, J.W. (1990), “A factor analytic study of logistics strategy”, Journal of Business Logistics, Vol. 11 No. 2, pp. 41-63.

McGinnis, M.A. and Kohn, J.W. (1993), "Logistics strategy, organizational environment, and time competitiveness", Journal of Business Logistics, Vol. 14 No. 2, pp. 1-23.

McGinnis, M.A. and Kohn, J.W. (2002), "Logistics strategy-revisited”, Journal of Business Logistics, Vol. 23 No. 2, pp. 1-17.

McGinnis, M.A., Kohn, J.W. and Spillan, J.E. (2010), "A longitudinal study of logistics strategy: 1990-2008”, Journal of Business Logistics, Vol. 31 No. 1, pp. 217-235. 
McGinnis, M.A., Spillan, J.E. and Virzi, N. (2012), "An empirical study comparing Guatemalan and United States logistics strategies", The International Journal of Logistics Management, Vol. 23 No. 1, pp. 77-95.

McGinnis, M.A., Harcar, T., Kara, A. and Spillan, J.E. (2012), "Cross-cultural validation of factorial structure of logistic strategy model: a three-country study", Journal of Transportation Management, Vol. 22 No. 2, pp. 25-44.

Pallant, J.F. (2007), SPSS Survival Manual: A Step by Step Guide to Data Analysis Using SPSS, 3rd ed., Open University Press, Mc-Graw Hill Education, Berkshire, p. 6.

Rai, A., Patnayakuni, R. and Seth, N. (2006), "Firm performance impacts of digitally enabled supply chain integration capabilities", MIS Quarterly, Vol. 30 No. 2, pp. 225-246.

Rodrigues, A.M., Stank, T. and Lynch, D.F. (2004), "Linking strategy, structure, process, and performance in integrated logistics", Journal of Business Logistics, Vol. 25 No. 2, pp. 65-94.

Rojas-Méndez, J.I. and Davies, G. (2005), "Avoiding television advertising: some explanations from time allocation theory", Journal of Advertising Research, Vol. 45 No. 1, pp. 34-48.

Schmitt, N. (1996), "Uses and abuses of coefficient alpha”, Psychological Assessment, Vol. 8 No. 4, pp. 350-353.

Spillan, J.E., Kohn, J.W. and McGinnis, M.A. (2010), "A study of logistics strategies in small versus large US manufacturing firms”, Journal of Transportation Management, Vol. 21 No. 1, pp. 43-62.

Stock, J.R. (2002), "Marketing myopia revisited: lessons for logistics", International Journal of Physical Distribution \& Logistics Management, Vol. 32 No. 1, pp. 12-21.

Transparency International (2011), "2011 Public-sector corruption index and 2011 bribery index: transparency international”, available at: www.transparency.org (accessed April 7, 2012).

US Central Intelligence Agency (2012), "World Factbook", available at: www.cia.gov (accessed May 7, 2012).

Wang, Q., Zantow, K., Lai, F. and Wang, X. (2006), "Strategic postures of third-party logistics providers in Mainland China", International Journal of Physical Distribution \& Logistics Management, Vol. 36 No. 10, pp. 793-819.

\section{Corresponding author}

Michael A. McGinnis can be contacted at: mam47@psu.edu
Logistic strategy and integration

179

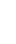


Reproduced with permission of the copyright owner. Further reproduction prohibited without permission. 